\title{
INFLUÊNCIA DA PROTEÇÃO DO ENXERTO NA PRODUÇÃO DE MUDAS DE ABACATE ${ }^{1}$
}

\author{
UBIRAJARA RIBEIRO MINDÊLLO NETO², ANDRÉ NUNES LOULA TORRES ${ }^{3}$, ELCIO HIRANO², ALVADI ANTÔNIO \\ BALBINOT JÚNIOR ${ }^{3}$, IRINEU OSNI BREY ${ }^{4}$, EDUARDO PETERS ${ }^{4}$
}

\begin{abstract}
RESUMO - O presente trabalho objetivou avaliar dois tipos de proteção do enxerto na produção de mudas de abacateiro $c v$. Herculano. O experimento foi conduzido em delineamento inteiramente casualizado, com dois tratamentos (T1: proteção do enxerto com saco de polietileno; T2: proteção do enxerto com parafilme) e seis repetições. As avaliações foram feitas após cinco meses da enxertia, nas quais foram determinadas as seguintes características: pegamento do enxerto, comprimento e diâmetro das brotações. A utilização de parafilme como proteção do enxerto aumentou o pegamento na enxertia.
\end{abstract}

Termos para indexação: parafilme, saco de polietileno, Persea americana, propagação.

\section{PROTECTION OF THE GRAFT IN THE PRODUCTION OF AVOCADO NUT NURSERY TREES}

ABSTRACT-The present work aimed to appraise two types of protection of the graft in the production of avocado nut nursery tree $c v$. Herculano. The experiment was led in a completely randomized design with two treatments (T1: polyethylene bag; T2: parafilm) and six replicates. The evaluations were made after five months of the grafting where were observed the following characteristics: successfulness of the graft, length and diameter of the sprouting. The parafilm used as protection of the graft increased the success of the grafting.

Index terms: parafilm, polyethylene bag, Persea americana, propagation.

O método tradicional de proteção do enxerto utilizado na produção de mudas de abacate é baseado na utilização de sacos de polietileno transparente, os quais são colocados de boca para baixo, envolvendo o enxerto, com a extremidade amarrada ao caule no portaenxerto, formando uma câmara úmida ao redor do garfo enxertado, protegendo o enxerto contra perda excessiva de água (Simão, 1998).

Segundo Koller (1984), o saco de polietileno, usado para cobrir o enxerto, tem a finalidade de conservar a umidade do ar, evitando a desidratação do garfo, sem impedir as trocas gasosas de $\mathrm{O}_{2}$ e $\mathrm{CO}_{2}$, importantes para o pegamento do enxerto. Outros materiais podem ser usados para a proteção do enxerto, como, por exemplo, parafilme. $\mathrm{O}$ parafilme constitui-se num plástico especial, bastante flexível, maleável e biodegradável, não necessitando ser retirado (Jacomino et al., 2000).

Em roseiras, Davies Junior et al. (1986) obtiveram bons resultados quando empregaram o parafilme na enxertia. Em adição, Jacomino et al. (2000), trabalhando com abacateiro $c v$. Fortuna, observaram que o parafilme apresentou melhores resultados de proteção do enxerto, quando comparado com saco de polietileno. Martin \& Bergh (1991), utilizando o parafilme como proteção do enxerto na $c v$. Hass, constataram, depois de 10 semanas da enxertia, comprimento de brotações em torno de $11,6 \mathrm{~cm}$ e, sem parafilme, comprimento de $6,1 \mathrm{~cm}$.

O objetivo deste trabalho foi verificar o efeito dos tipos de proteção do enxerto na produção de mudas de abacate, disponibilizando alternativas de tecnologia a viveiristas e produtores.

O trabalho foi desenvolvido em casa de vegetação da EMBRAPA Transferência de Tecnologia/SNT, Canoinhas-SC. As sementes utilizadas na produção dos porta-enxertos de abacate foram coletadas em frutos maduros da $c v$. Fuerte. Efetuou-se a remoção do endocarpo para facilitar a germinação, e para prevenir a infestação das sementes por agentes patogênicos, utilizou-se o produto comercial "Captan" a 0,25\%, aplicado em aspersão. Em seguida, as sementes foram acondicionadas em areia esterilizada, dentro de bandejas plásticas, as quais apresentavam quatro furos na parte inferior, e colocadas em fitotron, a temperatura de $25^{\circ} \mathrm{C} \pm 2{ }^{\circ} \mathrm{C}$ e umidade relativa do ar em torno de $72 \%$, para acelerar a germinação. No interior do fitotron, as bandejas plásticas que continham as sementes de abacate, foram colocadas em bandejas de alumínio. Colocou-se água até a metade nas bandejas de alumínio para acelerar a hidratação das sementes.
A semeadura foi realizada em setembro, com a base da semente para baixo, enterrada à profundidade de $2 \mathrm{~cm}$. Após 16 dias, as sementes germinadas no fitotron foram colocadas em sacos de polietileno de cor preta, com dimensões de $29 \times 24 \mathrm{~cm}$ contendo a mistura de $1 / 3$ de substrato comercial "plantmax", 1/3 de material da camada superficial $(10 \mathrm{~cm})$ de um CAMBISSOLO HÁPLICO tb Distrófico típico (Embrapa, 1999) e 1/3 de argila. Os sacos foram mantidos em casa de vegetação com temperatura e umidade relativa do ar de $27^{\circ} \mathrm{e} 70 \%$, respectivamente.

A enxertia da cultivar Herculano foi realizada em dezembro, quando as mudas apresentavam casca de coloração roxa, diâmetro do caule de $1 \mathrm{~cm}$ e altura de $35 \mathrm{~cm}$, utilizando o método de enxertia por garfagem no topo em fenda cheia. Foram utilizados garfos de ramos ponteiros semi-herbáceos, com $15 \mathrm{~cm}$ de comprimento e com ausência de medula branca, que é um tecido esponjoso branco que dificulta a soldadura dos tecidos do enxerto com os do porta-enxerto. Foi feito um corte horizontal no porta-enxerto a uma altura de $10 \mathrm{~cm}$ do nível do substrato e, posteriormente, com um canivete de enxertia, efetuou-se um corte longitudinal, abrindo-se uma fenda em forma de cunha, onde foi introduzido o garfo e depois amarrado no ponto de enxertia com parafilme. A enxertia foi realizada somente por um enxertador, para que não ocorresse variação nos resultados.

Para a proteção do enxerto, foram utilizados sacos de polietileno e parafilme. O saco de polietileno, com dimensões de 4 x $23 \mathrm{~cm}$, foi colocado, cobrindo o enxerto, e amarrado com fitilho ao porta-enxerto abaixo do ponto de enxertia, formando um ambiente com alta umidade ar, contribuindo para o pegamento do enxerto. $\mathrm{O}$ saco de polietileno foi retirado após o início da brotação. O parafilme foi aplicado, em espiral, do ponto de enxertia até a parte apical do enxerto, envolvendo todo o garfo.

As determinações foram realizadas cinco meses após a enxertia, sendo avaliadas as seguintes características: pegamento do enxerto; dado em percentagem, comprimento de brotações, por planta, deteminado com régua, e diâmetro de brotações, determinado com paquímetro.

Utilizou-se o delineamento experimental inteiramente casualizado, com dois tratamentos (T1:proteção do enxerto com saco de polietileno, e T2: proteção do enxerto com parafilme), com seis repetições. Cada unidade experimental foi composta por cinco plantas. Os dados coletados foram submetidos à análise de variância e as médias

(Trabalho 164/2003). Recebido: 31/10/2003. Aceito para publicação: 02/04/2004.

${ }^{2}$ Eng. Agr. M.Sc. Embrapa Transferência de Tecnologia/SNT Canoinhas, Rod. BR. 280, km 219, Caixa Postal 317, CEP 89 460-000, Canoinhas-SC, Fone: (47) 6240127; ubirajara.encan@embrapa.br, elciohirano.encan@embrapa.br

${ }^{3}$ Eng. Agr. M.Sc. Empresa de Pesquisa Agropecuária e Extensão Rural de Santa Catarina/Epagri-Estação Experimental de Canoinhas. Rod. BR. 280, km 219, Caixa Postal 216, CEP 89 460-000, Canoinhas-SC, Fone: (47) 624-1079, antorres@epagri.rct-sc.br, balbinot@epagri.rct-sc.br

${ }^{4}$ Técnico Agrícola, Embrapa Transferência de Tecnologia/SNT Canoinhas, Rod. BR. 280, km 219, Caixa Postal 317, CEP 89 460-000, Canoinhas-SC, Fone: (47) 6240127, eduardo.encan@embrapa.br, irineu@netnorte.com.br 
TABELA 1- Efeito da proteção do enxerto na propagação de mudas de abacateiro $c v$. Herculano, cinco meses após a enxertia.

\begin{tabular}{cccc}
\hline Proteção do enxerto & Pegamento do enxerto $(\%)^{2}$ & Comprimento médio de brotações $(\mathrm{cm})$ & Diâmetro médio de brotações $(\mathrm{mm})$ \\
\hline Saco de polietileno & $47,37 \mathrm{a}^{1}$ & $4,79 \mathrm{~b}$ & $3,31 \mathrm{~b}$ \\
Parafilme & $78,34 \mathrm{a}$ & $8,84 \mathrm{a}$ & $4,60 \mathrm{a}$ \\
\hline C.V. $(\%)$ & 17,56 & 21,61 & 12,42
\end{tabular}

${ }^{1}$ Médias seguidas de mesma letra na coluna não diferem entre si, pelo teste de Tukey, a 5\% de probabilidade.

${ }^{2}$ Dados transformados em arc-sen $\sqrt{x / 100}$

comparadas pelo teste de Tukey, ao nível de 5\% de probabilidade. Os dados de pegamento do enxerto foram transformados em arc-sen $\sqrt{x / 100}$.

Não ocorreram diferenças significativas no pegamento do enxerto (Tabela 1); entretanto, observa-se que, quando utilizamos o parafilme na proteção dos garfos de abacate, ocorreu um aumento no percentual de pegamento, comparado à proteção com o saco de polietileno. Neste sentido, os resultados obtidos neste experimento estão de acordo com as observações feitas por Davies Junior et al. (1986), considerando o parafilme um bom material de proteção do enxerto na propagação de mudas de abacate e também evidencia uma concordância com os obtidos por Jacomino et al. (2000) que, utilizando diferentes proteções do enxerto em mudas de abacateiro, verificaram pegamentos do enxerto na ordem de $80,26 \%$ quando utilizado o parafilme para proteção do garfo, enquanto, utilizando saco de polietileno, o pegamento caiu para $36,19 \%$.

O comprimento e o diâmetro das brotações alcançaram os melhores resultados quando foi usado o parafilme como proteção do enxerto em comparação ao saco de polietileno (Tabela 1). Jacomino et al. (2000) também verificaram que o uso de parafilme proporciona maior diâmetro de brotações; entretanto, o comprimento de brotações diminuiu quando utilizado o parafilme como proteção do enxerto. Contudo, no presente trabalho, os resultados estão de acordo Martin \& Bergh (1991) que, em experimento realizado na Califórnia com a $c v$. Hass, verificaram que o uso de parafilme aumentou o comprimento de brotações.

Concluímos que o parafilme foi o melhor método de proteção do enxerto comparado com o saco de polietileno na propagação de mudas de abacate. A utilização de parafilme para a proteção do enxerto pode ser vantajosa para o viveirista e o produtor, pois proporcionou maior quantidade de pegamento da enxertia comparado com o método usual.

\section{REFERÊNCIAS BIBLIOGRÁFICAS}

DAVIES JUNIOR, F.T.; HAMBRICK, C.E.; FANN, Y.; PEMBERTON, N.B. Grafting and adventitious root formation of Texas field rose bushes. Acta Horticulturae, Leuven, n.189, p.89-100, 1986.

EMBRAPA. Centro Nacional de Pesquisa de Solos (Rio de Janeiro-RJ). Sistema brasileiro de classificação de solos. Brasília: Embrapa Produção de Informação: Rio de Janeiro: Embrapa Solos, 1999. 412p.

JACOMINO, A.P.; MINAMI, K.; KLUGE, R.A.; KISHINO, A.Y. Métodos de proteção de enxerto na produção de mudas de mangueira, abacateiro e nogueira-macadâmia. Pesquisa Agropecuária Brasileira, Brasília, v.35, n.10, p.1985-1990, 2000.

KOLLER, O.C. Abacaticultura. Porto Alegre: Ed. Da Universidade/ UFRGS, 1984.138p.

MARTIN, G.; BERGH, B. Avocado Topworking Update 1990. In: WORLD AVOCADO CONGRESS, 2., 1991, Orange. Proceedings... Orange: University of California, Riverside and California Avocado Society, 1991. v.1.p. 365-371.

SIMÃO, S. Tratado de fruticultura. Piracicaba: FEALQ, 1998. 760p. 